Volume 9 No.2, March - April 2020

International Journal of Advanced Trends in Computer Science and Engineering

Available Online at http://www.warse.org/IJATCSE/static/pdf/file/ijatcse154922020.pdf

https://doi.org/10.30534/ijatcse/2020/154922020

\title{
Use of Information Technology in Crime Investigation
}

\author{
Nguyen HuyBinh \\ $\mathrm{PhD}$ in Law \\ Deputy head of the criminal police Department, people's police Academy \\ Hanoi, Vietnam
}

\begin{abstract}
In litigation, transparency is the primary method of information security. Any citizen can count on legal services, the protection of a lawyer in a case of any complexity. And also on the motivated, reasoned conclusion. The Criminal Code allows the closure of proceedings to ensure the protection of the participant, at the risk of disclosure of intimate aspects of life or state secrets, high-tech ideas and achievements. The investigation should be prompt, evidence-based, so it's important to apply IT's advances, such as Big Data and Data Mining, to identify new connections not lying on the "visible surface" of the case. As well as for reduction of complexity, reduction of versions and prevention, etc. With the emergence of new, systemically and structurally complex tasks, the use of digital technologies and approaches in the investigation of crimes becomes vital not only in a portable sense for some suspects.

Society often does not demand punishment ("punishment for the sake of punishment"), it demands prevention of it in the future (public order and confidence in tomorrow). Prevention of criminal acts is possible on the basis of IT, information systems of justice, digital transformations in society, law and economy. This article provides a systematic analysis of ways, methods and problems of IT application in crime investigation. A systematic analysis of the possibilities of updating was carried out, which resulted, in particular, in a list of the most relevant in the investigation of IT crimes. In order to assess the system profile of the suspect, a Bayesian approach is proposed, and as a method of implementing the process - a manyagency method, popular in complex, non-linear problems.
\end{abstract}

Key words: investigation, technology, information, criminal, crime, use, system.

\section{INTRODUCTION}

Investigating IT crimes requires speed, completeness, accuracy, evidence and reduced uncertainty. A prompt, efficient and complete investigation will require the involvement of IT, which will reduce the complexity of the investigation. For example, in cases of various regions of South-East Asia concerning the automatic identification of a counterfeit banknote [1], forensic expert identification of a firearm of crime [2], the use of genetic markers [3], etc.

The diversity of IT-related [4] crimes is also on the rise. For example, in [5] 16 types of crimes was classified, which is much more than traditionally considered by criminologists. Such preventive prevention is related to operational analytics, Big Data processing, Data Mining [6] and other intelligent systems.

The main task is to prevent the crime. Research shows that society attempts to influence the criminal situation more through criminal prosecution and punishment. This contradicts the conclusions of schools of pedagogy, psychology and philosophy. The values of the social order and the State must be protected, and their norms must be respected, starting with the family, children [7] and ending with the institutions of society.

Prevention of a criminal act occurs through general (social) prevention (by reaction or collective reaction) and special prevention. Both use the capabilities of IT, justice information systems, and cloud structures [8]. Digital transformations in society, economy, and justice technologies [9] allow assessing risks and managing prevention in a relevant way. For example, taking into account the risks and prospects of an individual State (e.g. [10]) or the prospects for early release in a separate prison system [11], taking into account its systemic characteristics [12].

\section{INFORMATION TECHNOLOGY IN CRIME INVESTIGATION}

Development of "digital justice" and Industry 4.0 [13] allows re-engineering the IT infrastructure of the crime investigation system. Given that the investigator processes a sufficient amount of data, informatization of the investigation is a pressing task. It's necessary to take into account deviant behavior [14], to process, analyze and "filter" without loss of information value all necessary information, while automating routine.

For example, Vietnam successfully implements a distributed, three-tier system:

1) level of the region, province;

2) level of municipal body's department; 
Nguyen HuyBinh, International Journal of Advanced Trends in Computer Science and Engineering, 9(2), March - April 2020,1909 - 1912

3) the investigator's intellectual workplace (ARM "Investigation"), which is based on forensic methods (on crimes and situations taken by decisions) [15].

The Investigation system provides dialogue support that includes (but is not limited):

1) obtaining information about the victim;

2) issuing recommendations on investigation planning;

3) analysis and classification of events (for example, by episodes);

4) planning investigative actions;

5) automation of the case management process, etc.

The main are subsystems:

1) automation of accounting, control ("Control");

2) support the base of criminals, investigators etc. ("Statistics");

3) support of methodological information ("Help");

4) operational reference automated accounting ("Accounting");

5) automated auxiliary subsystems (secretariat, personnel, accounts, workplaces, etc.).

Criminals actively use IT, WWW applications, automated and intelligent environments. Therefore, only the intellectual development of investigative and investigative structures and processes can significantly improve the efficiency of crime investigation. Within Vietnam, thousands of specialized AWS have to be deployed (for each second employee - mandatory).

\section{VIRTUAL INVESTIGATION OR SITUATIONAL (IMITATING) MODELING OF PROCESS OF INVESTIGATION}

Virtual investigation is primarily required in the investigation and trial of the following situations:

1) finding a solution with no time reserve, the possibility to resort to offline investigation;

2) "distributed" proceedings, intensive remote communication with colleagues-professionals, participants of the case, etc.

Shortcomings it's also available at virtuality: unreliability, insecurity [16], etc. In addition, the reasons for the weak use of social networks and their capabilities by communities in the investigation of crimes are considered [17]:

1) complexity of information-logical search;

2) weak verification of data and facts, evidence;

3) bad formalization;

4) duration of the whole investigation cycle;

5) the "reverse side" of mobility or difficulty in obtaining mobile data, although such automatic retrieval systems are being developed, for example, the UFED system [18];

6) labour intensity of procedural processing of the case;

7) complexity of procedural use of results [19], etc.
Virtual investigation and use of social and network resources [20], carried out in the information infrastructure of the case, in intelligent systems, should:

1) be unambiguous and legally understandable or "understandable at the level of intuition";

2) to state clearly the objectives, logical sequences of legal conclusions of the parties and their validity;

3) have a complete structure, be orderly and take into account possible risks, for example, the psychological state of a person tested on an information and logical instrument (in particular, on a technologically saturated polygraph - although the polygraph does not determine the reason why a person reacted to the question in this way, only fixing the reaction);

4) enable the use of automated and intelligent systems, databases and knowledge (for example, fingerprint, guaranteeing the quality of prints and fingerprint formula, their rapid updating during investigation);

5) to be able to update expert judgements, as well as intelligent (expert) systems based on them, because much in such systems depends on the qualification of the expert, his competences and sense of detail, their reflection in the expert opinion.

Note IT, primarily used in the investigation of cases, they can be classified as one of the following types:

1) cognitive (for obtaining, storing and updating legal knowledge and decisions in investigation);

2) tools (to develop modern IT investigation tools);

3) communicative (to establish or maintain the necessary links in the investigation);

4) applied to solve specific tasks of investigation, for example, program "FORVER" finding the criminal according to the data of the crime in the similar cases, helping to draw up quite successfully a portrait of the offender [21]).

\section{RESULT}

The system analysis of the properties of the ergency of [22] crime investigation systems and the possibilities of updating modern IT in the investigation, allows to draw the following conclusion.

In addition to traditionally used databases, computer office (client-server and working group technologies), mathematical and infological modeling, CASE, multimedia and others, the following technologies are relevant in crime investigation:

1) DataMining and BigData, for example, search for dependencies and trends hidden in volume data and DB by crimes;

2) multi-dimensional scaling, taxonomy and cluster analysis, for example, division of objects, subjects, processes into classes with assessment of proximity within class, weights and ranks;

3) expert, intelligent systems for automated decisionmaking based on expert judgment (using specially developed, for example, product knowledge bases); 
4) virtualization and visualization, animation, for example, building a photobot or animation character (movie) investigation, as in the LightWaveModeler environment [23];

5) neural networks, for example, recognition by behavior at the train station or at the airport of suspicious persons [24];

6) cognitive, allowing to compare different investigation strategies, allowing to reduce systemic uncertainty, especially at the initial stage of investigation;

7) fuzzy technologies or decision-making using the apparatus of fuzzy connections, facts and sets of objects and subjects of the criminal case under consideration;

8) multi-agent or distributed systems of interacting agents [25], programs that actively and adaptively interact with each other in the search for a solution to complex and poorly structured problems [26].

These instrumental IT are the basis of the construction of the system "Investigation." Electronic investigation and investigation of the case is not evolving rapidly, like electronic business.

Problems with electronic-digital signature, lack of training of lawyers in the field of high technologies also affect. While in civil cases the Act recognizes evidentiary value, such as a digital signature, various conflicts arise in criminal cases. For example, a digital document is not evidentiary in a number of countries, as the law does not establish the procedure and procedure for the circulation of documents, as well as the details of authenticity. Particular consideration should be given to the lateness of many criminal IT crimes, fraud in the web environment [27].

"Legal" nihilism is also affected in many provinces, leading to negative or uncertain (ambiguous) attitudes to the severity and possibility of punishment. For example, fraud is already loosely regulated by law, and high-tech fraud is difficult to identify on time. Therefore, there are many crimes in this sphere, trends tend to indicate an increase in dynamics.

You should also protect your document files and system securely. The use of contactless smart cards of dual protection (both key and PIN- code are needed) can help here. Biometric innovations require a legal framework, an expansion of the Law.

You should also apply hashed values to generate and store keys on the system, automatically reloading it, reading it out at the next login from the administrator panel.

The system profile of the accused or suspect can be better and more complete if special programmes are used to narrow down the number of suspects. For example, by analyzing precedents, if all the necessary information is available in the knowledge base on them. Besides, with corresponding estimates of conditional probabilistic (for example, Bayesian) parameters describing the crime scene, the method of commission, etc. The withdrawal of the system (program) may not be a guaranteed conclusion at once, but will provide great assistance in investigative, operational and search activities.

Suppose that $\mathrm{P}(\mathrm{C})$ is the a priori probability of version $\mathrm{i}$ (participation of the $\mathrm{i}$-th suspect in the criminal case), and $\left.\left(C \mid Q_{i}, A_{i}\right)\right)$ is the predicate "asked question, $Q_{i}$ the answer is received $A_{i}$ ) Then we get by Bayes formula (for example, [28]):

$$
P\left(C \mid\left(Q_{i}, A_{i}\right), i=1,2, \ldots, n\right)=\frac{P\left(\left(Q_{i}, A_{i}\right) \mid C\right) P(C)}{\sum_{i=1}^{n} P\left(\left(Q_{i}, A_{i}\right) \mid C_{i}\right) P\left(C_{i}\right)} .
$$

The essence of the Bayesian approach: there is data of observations (investigative experiments, testimony of witnesses and others). Including the investigator's assumptions. They are subject to iterative refinement during observations. The updated knowledge of the links (objects and entities) is then generated. The likelihood factor is $P((Q, A) \mid C)$. According to the tests, it's possible to identify its plausibility for each version. Automatically, with self-learning of expert (intelligent) system and reduction of distribution entropy

$$
P\left(C \mid\left(Q_{i}, A_{i}\right), i=1,2, \ldots, n\right) .
$$

It's important to choose a $\mathrm{Q}$ question that minimizes conditional entropy in a known response, i.e. will eliminate uncertainty and allow a reasonable (and possibly evidentiary, verifiable) decision to be made.

The apparatus of many-agency systems, a system of intellectual intermediaries (for example, communication, infological), which help to make a decision taking into account not only legal, but also interests of social and business oriented, are well suited here.

\section{CONCLUSION}

A non-systemic approach to legal IT, information and legal systems is one of the most important reasons for the lack of effectiveness of the investigation. Despite the extensive class of existing technologies, forensic algorithms of traditional proceedings, the development of electronic investigation is not only a technological result, but also a systemic result.

There's a need to systematize, reassess the realities of modern investigations, highlight systemic features and build on them the evidence base of information technology investigation. It's promising, for example, to use blockchain technologies in remote proceedings, ensuring the security of the process. The provisions of the laws of countries should be amended and expanded until we provide a legal basis for the use of high technology in criminal investigations.

But the process of intellectual investigation related to technology does not end there. Lawyers should work with physics engineers, mathematics programmers, social psychologists and educators to create effective systems for identifying and evaluating relevance, search, optimization, analytics, management and monitoring. 


\section{REFERENCES}

1.K. Suneet, Mahipal S.S, K. Rajeev, P. Kapil, K. P. Ramesh, S. Vaibhav. Forensic Analysis of Security Features in Indian Currency Denomination Of $\square 500$ Authentication and Recognition ThroughDocucenterNirvis Instrument. 2020 // J. Forensic Sci \& Criminal Inves. 13(3): 555865. DOI: 10.19080/JFSCI.2020.13.555865

2.J. Anjali, C. Saloni and M. Suryakant Bullet Fingerprinting Analysis by Digital Comparison Microscope // J. Forensic Sci\& Criminal Inves. 2019. 12(5): 555847. DOI: 10.19080/JFSCI.2019.12.555847

3.L. Jinding and Zh. Gengqian. DIP-Linked DNA Polymorphism-A Novel Type of DNA Marker to Detect Mixture DNA // J. Forensic Sci\& Criminal Inves. 2019. 12(5): 555850. DOI: 10.19080/JFSCI.2019.12.555850

4.A.S. Shatalov. Phenomenology of crimes committed using modern information technologies // Law. Journal of the Higher School of Economics. 2018.№2. pp.68-83.

5.M. N.Hassan. 16 Types of Crime Prevention. J. Forensic Sci\& Criminal Inves. 2019. 11(3): 555814. DOI: 10.19080/JFSCI.2019.11.555814

6.I.A.T. Hashem, I. Yaqoob, N.B. Anuar, S.Mokhtar, A. Gani and S.U.Khan The Rise of «Big Data» on Cloud Computing: Review and Open Research Issues // Information Systems. 2015.vol.47. - pp. 98-115.

7.A. Najafi and H. Ali. Prevention of Delinquency and Local Police // J. Legal Research, Law School, ShahidBeheshti University. 1997. pp.18-20.

8.A. O. Douglas and P. White. Current State of Forensic Acquisition for IaaS Cloud Services // J. Forensic Sci\& Criminal Inves. 2018. 10(1): 555778. DOI: 10.19080/JFSCI.2018.10.555778.

9.M. Petrov, V. Burov, M. Shklyaruk, A. Sharov. State as platform. (Cyber) state for digital economy. Digital transformation. - Moscow. 2018: CSD.

10.C. Korchagin\& B. Polshikov. Digital economy and the transformation of public administration. Risks and prospects for Russia // Free thought. 2018. №1 (1667). pp. 23-36.

11.N. H. Fung \& W. W. Ngo. Institute of Parole in Various Countries and its Improvement in Viet Nam//Penal Enforcement Law. 2018. Vol. 13(1-4), №3. pp. 329-333.

12.Government Regulation on Prisons (Viet Nam) (2020). Available at: URL: https://luatvietnam.vn/an-ninh-trattu/nghi-dinh-60-cp-chinh-phu-2737-d1.html (address date: 30.03.2020).

13.E.V. Balatski. Global Challenges to the Fourth Industrial Revolution // Terra Economics.2019. 17(2), pp.6-22. DOI: 10.23683/2073-6606-201917-2-6-22.

14.V.B. Salakhov,T.I. Shulga et al. Dynamics of The Value-Motivation Sphere Under The Influence of SocioPsychological Correction in a Person Prone To Deviant Behavior // Modern J. of Language Teaching Methods (MJLTM). 2018.vol.8, iss.12. DOI:10.26655/mjitm.18.12.1.

15.V.M. Kaziev, B.V. Kazieva\&K.V. Kaziev. Basics of legal informatics and informatization of legal systems (2nd ed.), INFRA-M.2017-Moscow. -336 p.

16.N.V. Olinder\&E.A. Gamburov. On the Results of the Experiment "Search and Perception of Identity Information on the Internet" and its Use in Crime Investigation // Forensic Expert.2017. No. 4. -pp.29-31.
17.V.M. Kaziev. Positive and negative consequences of informatization of legal systems of society/Mathematical methods and information and technical means. Materials of the X All-Russian Scientific and Practical Conference. 2014. pp.133-135.

18.A.M. Bagmet, V. V. Bychkov\&S.U. Skobelin. Obtaining information contained in mobile communication facilities using a universal judicial information extraction device (UFED): methodological recommendations / Institute of Advanced Training of the Investigative Committee of the Russian Federation. Moscow. 2013.

19.A.N. Kolycheva. Some Aspects of Recording of Evidentiary Information Stored on Internet Resources // Journal of Udmurt University (Economics and Law).2017. vol.27, N2. -pp.109-113.

20.E.A. Gambarov. On the Question of the Method of Using Social Networks in the Work of the Investigator // Law Gazette of the University of Samara. 2017. vol.3, N3. -pp.137-141.

21.V. Yu. Tololutsky. Use of information technologies in the discovery and investigation of murders // Electronic educational and methodological manual. National Research University named after N.I. Lobachevsky. 2012. $151 \mathrm{p}$.

22.V.M. Kaziev. Introduction to analysis, synthesis and modeling of systems. -M.: Binom. Knowledge Lab. Intuit.ru. 2007. 244 p.

23.Introduction to Lightwave Modeler (2020). Available at URL: https://www.schooltube.com/media/Intro to Lightwave Modeler/1_ug0cnx1p (contact date: 30.03.2020).

24,I.A. Spirin. Research and Application of Eye-Tracking Technology on Humans//Young Scientist, 2016. No. 2 (106), pp.227-230. Available at URL: https://moluch.ru/archive/106/25349/ (contact date: 29.03.2020).

25.G.B. Kleiner, M.A. Fishachuk\&D.V. Ushakov. Agentoriented model of professional expertise and decisionmaking in support of selected socially significant initiatives // Terra Economics.2019. vol. 17(2), pp.23-39. DOI: $10.23683 / 2073-6606-2019-17-2-23-39$

26.D.V. Bahteev. Transition from probabilistic knowledge to reliable and sufficient in the process of solving and investigating crimes: issues of theory and practice. Thesis... Candidate of Law (12.00.12). Ural Law University. 2015. 199 p.

27.A.A. Engelhardt. Issues of fraud qualification in the field of computer information//Law. Journal of the Higher School of Economics. 2016. №4. -pp.86-95.

28.E.T. Jaynes. Probability Theory: The Logic of Science Cambridge University Press. 2003. ISBN 0-521-59271-2 